\title{
Analysis of the Labial Gland Secretions of the Male Bumblebee Bombus griseocollis (Hymenoptera: Apidae)
}

\author{
Andreas Bertsch ${ }^{\mathrm{a}}$, Horst Schweer ${ }^{\mathrm{b}, *}$, and Andreas Titze ${ }^{\mathrm{a}}$ \\ a Department of Biology, Philipps-University Marburg, Karl-von-Frisch-Str. 8, \\ D-35032 Marburg, Germany \\ b Department of Pediatrics, Philipps-University Marburg, Deutschhausstr. 12, \\ D-35033 Marburg, Germany. Fax: +49-6421-2865724. \\ E-mail: schweer@med.uni-marburg.de \\ * Author for correspondence and reprint requests \\ Z. Naturforsch. 59c, 701-707 (2004); received June 22, 2004
}

The labial gland secretions from males of the bumblebee Bombus (Separatobombus) griseocollis De Geer, a bumblebee exhibiting perching behaviour, were analysed by gas chromatography/mass spectrometry (GC/MS) in the electron impact and positive ion chemical ionization mode. The major compound of the complex mixture of alkenols, acetates, hydrocarbons, wax type esters and steroids is tetradecyl acetate, considerable amounts of hexadecyl, geranyllinaloyl, geranylgeranyl, docosyl, tetracosenyl and hexacosenyl acetate were also found. 1,3-Tetradecanediol diacetate, detected as a minor component, has not yet been identified in male bumblebee labial gland secretions. Besides small amounts of primary alcohols (tetradecanol and hexadecanol) the tertiary alcohol geranyllinalool (3,7,11,15-tetramethyl-hexadeca-1,6,10,14-tetraene-3-ol) was also present. The primary alcohols were also present as esters of butanoic, dodecanoic, tetradecanoic, and hexadecanoic acid. Besides the usual mixture of un- and mono-unsaturated straight chain hydrocarbons, the labial gland contains the isoprenoid hydrocarbons $\beta$-springene [ $6 E, 10 E)-7,11,15$-trimethyl-3-methylenehexadeca-1,6,10,14-tetraene] and two isomers of $\alpha$-springene $[(3 Z, 6 E, 10 E)$ - and $(3 E, 6 E, 10 E)$ $3,7,11,15$-tetramethyl-hexadeca-1,3,6,10,14-pentaene]. The close relationship in chemical composition in male bumblebees with perching and flight pass behaviour is discussed.

Key words: Bombus griseocollis, Geranyllinalool, Springene, 1,3-Tetradecanediol Diacetate

\section{Introduction}

According to their premating behaviour, male bumblebees can be classified into three main groups (Schremmer, 1972; Lloyd, 1981; Bergman, 1997; Hovorka et al., 1998), as species exhibiting 1) patrolling behaviour, in which males establish flight paths with scent marks, 2) perching behaviour, in which males wait individually at prominent places, and dart passing queens or other moving objects, and 3) nest entrance waiting behaviour, in which males, often in groups, wait for emerging queens right at the nest entrance.

The patrolling behaviour is the most common type of premating behaviour among the bumblebee and cockoo-bumblebee species. Since Frank (1941) described this flight path activity of male bumblebees in detail, there was a growing interest in this peculiar behaviour of male bumblebees: a long-lasting, energy consuming daily flight activity (Bertsch, 1984) along fixed routes marked by scent produced in the cephalic part of the labial glands (Kullenberg et al., 1973). The perching behaviour and the nest entrance waiting behaviour are less common, less investigated and consequently not well understood.

Males of Bombus griseocollis belong to the group of large-eyed males exhibiting the perching behaviour. Bumblebees with this type of premating strategy occur world-wide, e.g. Bombus mendax and B. confusus in Europe, B. asiaticus, B. rufofaciatus and B. kashmirensis in Asia and B. nevadensis and B. griseocollis in North America. In these species, scent marking of their perching site was observed (Haas, 1949; Alcock and Alcock, 1983; Williams, 1991). Only B. confusus males were claimed to be entirely optically orientated in searching for mates without use of male pheromones (Schremmer, 1972). Therefore this species provided an example of a bumblebee species not using scent secretions in premating behaviour (Morse, 1982; Free, 1987). However Hovorka et al. (1998) found recently that $B$. confusus has a fully developed cephalic part of the labial gland. The secretion of this gland is used in scent marking 
the perching sites (Kindl et al., 1999). Only labial gland secretions from a few species of North American male bumblebees were investigated (Bergström et al., 1996; Bertsch et al., 2004) with no information on labial gland secretions of the subgenus Separatobombus (restricted to North America). Therefore we investigated the labial glands of B. (Separatobombus) griseocollis, a bumblebee with large-eyed males which scent mark perch sites in shady places in late summer (Alcock and Alcock, 1983).

\section{Materials and Methods}

Materials

Males of B. (Separatobombus) griseocollis De Geer were collected in late August 2003 in the area of Medford (Oregon, USA), where the species is abundant. The border of the wings of all males used for gland preparation was smooth, indicating young and active males. Old males can easily be rejected by their frayed wings. The males were then transported alive to the laboratory. In order to get \pm filled glands, they were fed honey solution for a few days before they were frozen after a short flight activity early in the morning. The cephalic part of the labial glands was dissected from the head of males in frozen condition and placed in vials (glands from 5 males per vial) containing $0.2 \mathrm{ml}$ pentane.

\section{$G C / M S$}

A Finnigan MAT TSQ700 gas chromatograph/ tandem mass spectrometer was employed. Gas chromatography was carried out on a Hewlett Packard Ultra 1 column $(50 \mathrm{~m}, 0.2 \mathrm{~mm}$ i.d., $0.11 \mu \mathrm{m}$ film thickness) in the splitless mode with helium as carrier gas at an inlet pressure of 300 $\mathrm{kPa}$. Initial temperature of $120^{\circ} \mathrm{C}$ was held for $1 \mathrm{~min}$, then increased at $8 \% \mathrm{~min}$ to $280^{\circ} \mathrm{C}$, at $3 \%$ min to $310^{\circ} \mathrm{C}$ and at $1 \% \mathrm{~min}$ to $320^{\circ} \mathrm{C}$. This temperature was held for $10 \mathrm{~min}$. Mass spectrometer conditions were: interface temperature, $300{ }^{\circ} \mathrm{C}$; source temperature, $130{ }^{\circ} \mathrm{C}$; electron energy. 70 $\mathrm{eV}$; emission current, $0.2 \mathrm{~mA}$; and electron multiplier, $1400 \mathrm{~V}$. In the positive ion chemical ionisation mode ammonia CI gas pressure was $70 \mathrm{~Pa}$.

Compounds were identified by comparing their mass spectra with those of the NIST '02 Library (National Institute of Standards and Technology, USA) and coinjection with commercially available standards.

\section{Results}

The labial glands contain a mixture of acyclic diterpenes (alcohols, acetates and hydrocarbons) and various straight-chain fatty acid derivates (alcohols, esters, and both saturated and unsaturated hydrocarbons with 21 to 31 carbon atoms in chain length). A typical chromatogram for the labial

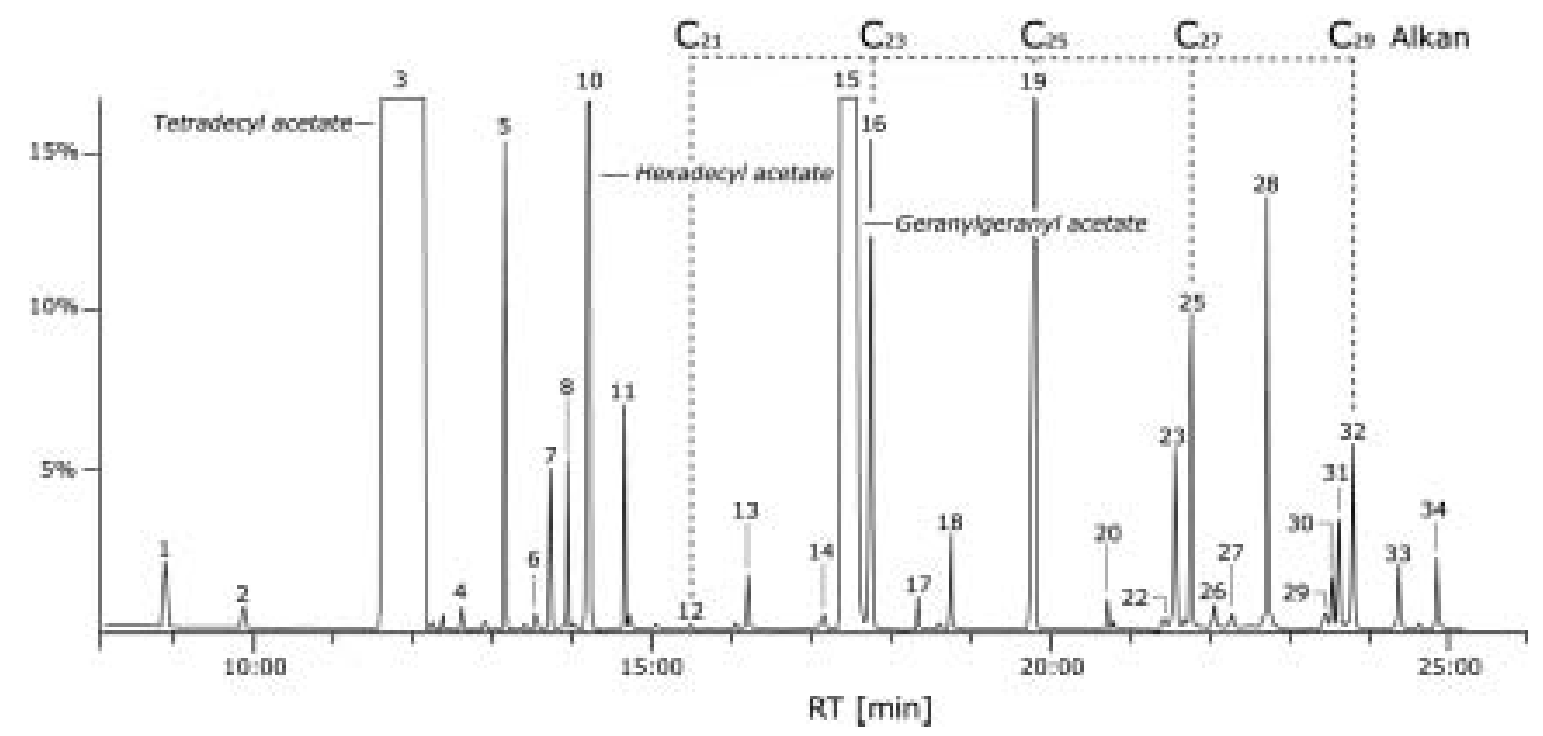

Fig. 1. Gas chromatogram of the labial gland secretion of Bombus (Separatobombus) griseocollis males up to $26 \mathrm{~min}$ retention time. 
gland secretions of B. (Separatobombus) griseocollis is given in Fig. 1 and the compounds are summarised in Table I. The major compound was tetradecyl acetate (Fig. 1, peak 3) and considerable amounts of hexadecyl acetate (peak 10) and geranylgeranyl acetate (peak 15; two isomers: shoulder at 17:27 min, main peak at 17:36 min) were detected. Minor amounts of dodecyl acetate (peak 1), geranyllinaloyl acetate (peak 14), docosyl acetate (peak 20), tetracosenyl acetate (peak 28), and hexacosyl acetate (peak 34) complete the pattern of acetates found. Small amounts of tetradecanol (peak 2), hexadecanol (peak 4) and geranyllinalool (peak 9) were also identified.

Besides the acetates 1,3-tetradecanediol diacetate was found (peak 11). In the positive CIspectrum the ions $[\mathrm{M}+\mathrm{H}]^{+}(m / z, 315),\left[\mathrm{M}+\mathrm{NH}_{4}\right]^{+}$ $(m / z, 332),\left[\mathrm{M}+\mathrm{H}-\mathrm{CH}_{3} \mathrm{COOH}\right]^{+}(m / z, 255)$ and $\left[\mathrm{M}+\mathrm{NH}_{4}-\mathrm{CH}_{3} \mathrm{COOH}\right]^{+}(\mathrm{m} / z$ 272) were observed. Base peak in the EI-spectrum (Fig. 2) was $\left[\mathrm{CH}_{3} \mathrm{CO}\right]^{+}(\mathrm{m} / \mathrm{z}, 59)$. The $[\mathrm{M}]^{+\cdot}$ ion $(\mathrm{m} / \mathrm{z}, 314)$ could not be detected. Subsequent fragmentation of $\mathrm{CH}_{3} \mathrm{COOH}$ resulted in fragments with $\mathrm{m} / \mathrm{z} 254$ and $\mathrm{m} / \mathrm{z}$ 194. Characteristic for 1,3-diol diacetates

Table I. Compounds of the labial glands of B. (Separatobombus) griseocollis males and structural evidence.

\begin{tabular}{|c|c|c|c|c|}
\hline Compound & No & $\mathrm{RT}^{\mathrm{a}}$ & $\mathrm{M}^{+\cdot b}$ & $\begin{array}{l}\text { Diagnostic mass spectral fragments } \\
(\mathrm{m} / \mathrm{z})^{\mathrm{c}}\end{array}$ \\
\hline Dodecyl acetate & 1 & $8: 53$ & 228 & $\mathbf{4 3}, \mathbf{5 5}, 61, \mathrm{M}-60=168$ \\
\hline Tetradecanol & 2 & $9: 50$ & 214 & $41,43, \mathbf{5 5}, 69,83 \mathrm{M}-18=196$ \\
\hline Tetradecyl acetate & 3 & $12: 06$ & 256 & $\mathbf{4 3}, \mathbf{5 5}, 61, \mathrm{M}-60=196$ \\
\hline Hexadecanol & 4 & $12: 37$ & 242 & $41,43, \mathbf{5 5}, 69,83, \mathrm{M}-18=224$ \\
\hline 7,11,15-Trimethyl-3-methylene-hexadeca-1,6,10,14-tetraene & 5 & $13: 08$ & 272 & $41,55, \mathbf{6 9}, 81$ \\
\hline$(3 Z, 6 E, 10 E)-3,7,11,15$-Tetramethyl-hexadeca-1,3,6,10,14-pentaene & 6 & $13: 30$ & 272 & $41,55,69,81$ \\
\hline$(3 E, 6 E, 10 E)-3,7,11,15$-Tetramethyl-hexadeca-1,3,6,10,14-pentaene & 7 & $13: 41$ & 272 & $41,55,69,81$ \\
\hline Tetradecyl butyrate & 8 & $13: 54$ & 284 & c $[71,89 ; 196]$ \\
\hline 3,7,11,15-Tetramethyl-hexadeca-1,6,10,14-tetraene-3-ol & 9 & $13: 58$ & 290 & $41,55, \mathbf{6 9}, 81$ \\
\hline Hexadecyl acetate & 10 & $14: 11$ & 284 & $\mathbf{4 3}, 55,61, \mathrm{M}-60=224$ \\
\hline 1,3-Tetradecanediol diacetate & 11 & $14: 37$ & 314 & $\mathbf{4 3}, 55,61, \mathrm{M}-60=254, \mathrm{M}-60-60=194$ \\
\hline Heneicosane & 12 & $15: 26$ & 296 & $43, \mathbf{5 7}, 71,85$ \\
\hline Octadecenyl acetate & 13 & $16: 11$ & 310 & $\mathbf{4 3}, 61, \mathrm{M}-60=250$ \\
\hline 3,7,11,15-Tetramethyl-hexadeca-1,6,10,14-tetraen-3-yl acetate & 14 & 17:09 & 332 & $41,43,69,81,93,147,161,203$ \\
\hline 3,7,11,15-Tetramethyl-hexadeca-2,6,10,14-tetraenylacetate & 15 & $17: 36$ & 332 & $41,43, \mathbf{6 9}, 81,93,263,289, \mathrm{M}-60=272$ \\
\hline Tricosane & 16 & $17: 45$ & 324 & $43, \mathbf{5 7}, \mathbf{7 1}, 85$ \\
\hline Tetradecyl octanoate & 17 & $18: 21$ & 340 & c $[127,145 ; 196]$ \\
\hline 3,7,11,15-Tetramethyl-hexadeca-2,6,10,14-tetraenyl butyrate & 18 & $19: 16$ & 360 & 69 \\
\hline Pentacosane & 19 & $19: 49$ & 352 & $43, \mathbf{5 7}, 71,85$ \\
\hline Docosyl acetate & 20 & $20: 43$ & 368 & $\mathbf{4 3}, 55,61, \mathrm{M}-60=308$ \\
\hline Hexacosane & 21 & 20:47 & 366 & $43, \mathbf{5 7}, 71,85$ \\
\hline Heptacosene & 22 & 21:26 & 378 & $43, \mathbf{5 5}, 69,83$ \\
\hline Heptacosene & 23 & $21: 33$ & 378 & $43, \mathbf{5 5}, 69,83$ \\
\hline Heptacosene & 24 & $21: 40$ & 378 & $43, \mathbf{5 5}, 69,83$ \\
\hline Heptacosane & 25 & 21:46 & 380 & $43, \mathbf{5 7}, 71,85$ \\
\hline 3,7,11,15-Tetramethyl-hexadeca-2,6,10,14-tetraenyl hexanoate & 26 & 22:04 & 388 & $43,55, \mathbf{6 9}, 81,93$ \\
\hline Tetradecyl dodecanoate & 27 & $22: 17$ & 396 & c $[183,201 ; 196]$ \\
\hline Tetracosenyl acetate & 28 & $22: 43$ & 396 & $\mathbf{4 3}, 55,61, \mathrm{M}-60=336$ \\
\hline Nonacosene & 29 & $23: 29$ & 406 & $43,55, \mathbf{5 7}, 69,83$ \\
\hline Nonacosene & 30 & $23: 33$ & 406 & $43,55, \mathbf{5 7}, 69,83$ \\
\hline Nonacosene & 31 & 23.38 & 406 & $43,55, \mathbf{5 7}, 69,83$ \\
\hline Nonacosane & 32 & 23:50 & 408 & $43, \mathbf{5 7}, 71,85$ \\
\hline Tetradecyl tetradecanoate & 33 & $24: 23$ & 424 & c $[211,229 ; 196]$ \\
\hline Hexacosyl acetate & 34 & $24: 52$ & 424 & $43, M-60=364$ \\
\hline Hentriacontane & 35 & $26: 05$ & 436 & $43, \mathbf{5 7}, 71,85$ \\
\hline Tetradecyl hexadecanoate & 36 & $26: 42$ & 452 & ${ }^{c}[209,227 ; 196]$ \\
\hline Ergosta-5,24-dien-3 $\beta$-ol & 37 & $27: 15$ & 398 & $\mathbf{5 5}, 314$ \\
\hline 24 -Ethyl-5-cholesten-3 $\beta$-ol (Sitosterol) & 38 & $28: 32$ & 414 & 57,414 \\
\hline 24-Ethylidene-5-cholesten-3 $\beta$-ol (Fucosterol) & 39 & $28: 41$ & 412 & $\mathbf{5 5}, 314$ \\
\hline
\end{tabular}

\footnotetext{
a Retention time.

b Molecular Ion.

c Ester (acylium ion of acid, protonated acid; alcohol M-18).
} 

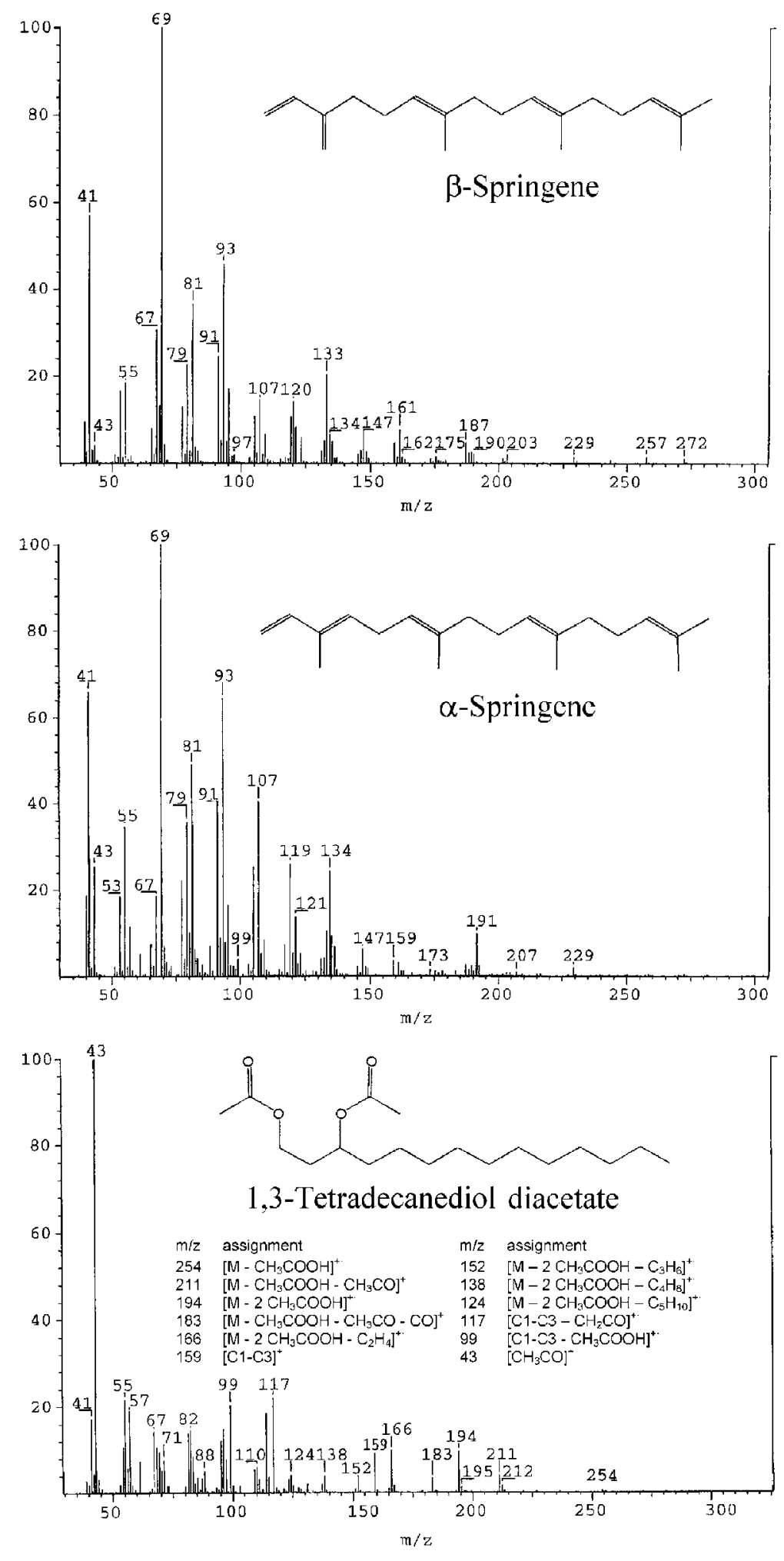

Fig. 2. EI-mass spectra of $\beta$-springene, $\alpha$-springene and 1,3-tetradecanediol diacetate. 
is an abundant $\alpha$-cleavage peak containing both acetate units $(\mathrm{m} / \mathrm{z}, 159)$ as observed in 1,3-hexanediol diacetate (Ross et al., 2001). Further fragmentation of $[\mathrm{C} 1-\mathrm{C} 3]^{+}$results in the ions $\left[\mathrm{C} 1-\mathrm{C} 3-\mathrm{CH}_{2} \mathrm{CO}\right]^{+}(\mathrm{m} / \mathrm{z}, 117)$ and $[\mathrm{C} 1-\mathrm{C} 3-$ $\left.\mathrm{CH}_{3} \mathrm{COOH}\right]^{+}(m / z, 99)$.

Compared to most other investigated male bumblebee labial glands, the proportion of hydrocarbons and esters was low. Only few wax type esters were found in the chromatogram (see Table I). Besides the usual compounds octanoic, dodecanoic, tetradecanoic and hexadecanoic acid esters of tetradecanol, the identification of tetradecyl butyrate (peak 8 ) is unusual. In the mass spectrum of tetradecyl butyrate the ion of $\mathrm{m} / \mathrm{z}, 89$ is the protonated butanoic- (= butyric) acid, the ion of $m / z 71$ can be attributed to the acylium ion of this acid and the ion of $m / z 196$ corresponds to tetradecanol [M-18]. The characteristic MS fragment ions of the alcohol and the acid part of these esters (Pepe et al., 1993) are good tools to detect small amounts of alcohols or acids, respectively, which are normally difficult to detect and identify in gas chromatograms.

Typical GCs also contain three diterpenes, isomers of springene. Their molecular ion has $\mathrm{m} / \mathrm{z}$ 272. Their mass spectra (Fig. 2) are identical with those of $\beta$-springene [ $6 E, 10 E)$-7,11,15-trimethyl3-methylene-hexadeca-1,6,10,14-tetraene, peak 5] and $\alpha$-springene (peaks 6 and 7) (NIST'02 Library). The relative retention times of $\beta$-springene, $(3 Z, 6 E, 10 E)-3,7,11,15$-tetramethyl-hexadeca-1,3,6, 10,14 -pentaene and $\alpha$-springene $[(3 E, 6 E, 10 E)$ 3,7,11,15-tetramethyl-hexadeca-1,3,6,10,14-pentaene] are as reported by Burger et al., 1981. As expected the mass spectra of $(3 Z, 6 E, 10 E)$ - and $(3 E, 6 E, 10 E)-3,7,11,15$-tetramethyl-hexadeca-1,3,6, 10,14-pentaene are nearly identical.

The tertiary alcohol geranyllinalool can easily be dehydrated resulting in the springene isomers. (3E,6E,10E)-3,7,11,15-tetramethyl-hexadeca-1,3,6, 10,14-pentaene might also be formed from geranylgeraniol but dehydration of the primary alcohol is difficult. Besides the springenes, low amounts of geranyllinalool and geranyllinaloyl acetate could also be observed. Geranylgeraniol was not found in the chromatogram because esterification of geranylgeraniol is favoured, though the acetate, butyrate and hexanoate of geranylgeraniol were formed.

\section{Discussion}

\section{Alcohols, acetates and wax esters}

Of all the male bumblebees investigated, the secretions of $B$. (Separatobombus) griseocollis are most similar to the secretions of B. (Alpinobombus) balteatus (Svensson and Bergström, 1979), which also has tetradecyl acetate as main component and also contains esters of butanoic acid, currently the only evidence of butyrates in bumblebees. As B. (Alpinobombus) balteatus belongs to a different subgenus of Bombus and has males which scent mark a long lasting flight-path activity (Svensson, 1979), this is strong evidence that there is no fundamental difference in scent composition that defines premating strategy. The observations of Alcock and Alcock (1983) on B. (Separatobombus) griseocollis and Kindl et al. (1999) on B. (Confusibombus) confusus that no activity of virgin females (gynes) was detected in the vicinity of the perches and the scent marked surroundings of these perches make it very probable that, contrary to some theories, the scent marks are not signals for male-female interactions, but are used in malemale communication.

The labial glands of most bumblebee males with the patrolling premating behaviour contain a pattern of straight chain primary alcohols (C12C26). The corresponding acetates are often only found in minor amounts or as traces, sometimes they are completely absent and occur only as a result of the ageing process of the prepared glands. The secretions of male bumblebees with the perching premating behaviour differ in the occurrence of acetates as the main components. In $B$. (Confusibombus) confusus Z-9-octadecenyl acetate is the main component, accompanied by geranylcitronellol (3,7,11,15-tetramethyl-6,10,14-hexadecatrien-1-ol) as a secondary major component, in B. (Separatobombus) griseocollis tetradecyl acetate is the main component with geranylgeranyl acetate (3,7,11,15-tetramethyl-2,6,10,14-hexadecatetraenyl acetate) as the secondary major compound. A mixture of substances with high and lower volatility is characteristic for the scent producing glands in male bumblebees. Bergman and Bergström (1997) detected the main component, farnesol, of the labial glands of B. (Pyrobombus) pratorum in headspace samples from marked leaves, but could not detect geranylgeranyl acetate, also produced by the glands, in the headspace samples. Kindl et al. (1999) could show that gera- 
nylcitronellyl acetate, though present in the labial glands of $B$. (Confusibombus) confusus only in minor amounts, can be detected in headspace samples of the male-marked perch (dry flower head of Centaurea stoebe). It is likely, that these less volatile compounds remain detectable until the next day, helping the bumblebees to find and reconstruct the previous day's activity. Evaporation of alcohols and acetates is a first-order process (release rate is proportional to the amount of pheromone present) with long half-lives (Butler and McDonough, 1981; McDonough et al., 1989) strongly depending on size, weight and polarity of the compound molecule.

\section{Dialkenols and diesters}

Until now only compounds with one functional group have been identified in labial gland secretions of male bumblebees; the detection of 1,3tetradecanediol diacetate is unique. 1,16- and 1,15hexadecanediol diacetate have been detected in the abdominal defense glands of the butterfly Agraulis vanillae (Nymphalidae: Heliconiinae) by Ross et al. (2001). In mammalian skin surface lipids (a mixture of lipids from the epidermis and the sebaceous glands) diester waxes have been identified consisting of 1,2-alkanediols in which both hydroxyl groups are esterified to unsubstituted fatty acids (Downing, 1976). 2,3-Alkanediol (uropygiol) and 2,3-alkanediol diesters have been identified in the uropygial glands of hens (Haahti and Fales, 1967), turkeys and pheasants (Jacob, 1976). The identification of 1,3-alkanediols is restricted to plant epidermis waxes (Vermeer et al., 2003).

Alcock J. and Alcock J. P. (1983), Behaviour in two bumblebees, Bombus nevadensis auricomus and B. griseocollis (Hymenoptera: Apidae). J. Zool. 200, 561570 .

Applegren M., Bergström G., Svensson B. G., and Cederberg B. (1991), Marking pheromones of megabombus bumble bee males. Acta Chem. Skand. 45, 972974.

Avery J. W., Shatagati A., Turner A., Wheeler J. W., and Weldon P. J. (1993), $\beta$-Springene in the paracloacal gland secretions of the smooth-fronted caiman $(\mathrm{Pa}$ leosuchus trigonatus). Biochem. Syst. Ecol. 21, 533534.

Bergman P. (1997), Chemical communication in bumblebee premating behaviour. PhD Thesis, Göteborg University, Sweden.

\section{Isoprenoid hydrocarbons}

In labial gland secretions of B. (Pyrobombus) pratorum two isomers of farnesene (3,7,11-trimethyl-2,6,10-dodecatrien) could be identified, the only isoprenoid hydrocarbons detected in bumblebee labial glands so far (Valterová and Urbanová, 1997). $\alpha$ - and $\beta$-springene $[(3 E, 6 E, 10 E)-3,7,11,15-$ tetramethyl-hexadeca-1,3,6,10,14-pentaene and 7,11,15-trimethyl-3-methylene-hexadeca-1,6,10,14tetraene, respectively] detected in the labial glands of B. (Separatobombus) griseocollis are newly identified isoprenoid hydrocarbons in bumblebee secretions. $\beta$-Springene has been previously isolated from a diversity of organisms, including the paracloacal gland of reptiles [the American alligator (Ibrahim et al., 1998) and the smooth-fronted caiman (Avery et al., 1993)], the dorsal secretions of mammals [collared peccary (Waterhouse et al., 1996), the white-lipped peccary (Waterhouse et al., 2001) and springbok (Burger et al., 1978, 1981)] and the Dufour glands of insects [Australian ant Nothomyrmecia macrops (Billen et al., 1988), the Old World army ant Aenictus rotundatus (Oldham et al., 1994), the Ectoparasitoid Bracon hebetor (Fukushima et al., 1990; Howard et al., 2003) and, as a trace component, the stingless bee Nannotrigona testaceicornis (Cruz-Lopez et al., 2001)].

The closely related compound geranyllinalool (3,7,11,15-tetramethyl-hexadeca-1,6,10,14-tetraene-3-ol) also present in small amounts in the labial glands of B. (Separatobombus) griseocollis has been identified as component of the labial glands of the bumblebees species B. (Megabombus) distinguendus (Appelgren et al., 1991), up to now this was the only indication of a tertiary alcohol in male bumblebee labial glands (Valterová and Urbanová, 1997).

Bergman P. and Bergström G. (1997), Scent marking. Scent origin, and species specifity in male premating behaviour of two Scandinavian bumblebees. J. Chem. Ecol. 23, 1235-1251.

Bergström G., Bergman P., Appelgren M., and Schmidt J. O. (1996), Labial glands chemistry of three species of bumblebees (Hymenoptera: Apidae) from North America. Bioorg. Med. Chem. 4, 515-519.

Bertsch A. (1984), Foraging in male bumblebees (B. lucorum): maximizing energy or minimizing water load? Oecologia 62, 325-336.

Bertsch A., Schweer H., and Titze A. (2004), Analysis of the labial gland secretions of the male bumble bee Bombus perplexus Cresson (Hymenoptera: Apidae) fromt North America. Z. Naturforsch. 59c, 263270. 
Billen J. P. J., Jackson B. D., and Morgan E D. (1988), Secretion of the Dufour gland of the ant Nothomyrmecia macrops (Hymenoptera: Formicidae). Experientia 44, 715-719.

Burger B. V., LeRoux M., Spies H. S. C., Truter V., and Bigalke R. C. (1978), Mammalian pheromone studies III. $(E, E)-7,11,15$-trimethyl-3-methylene-hexadeca1,6,10,14-tetraene, a new diterpene analogue of betafarnesene from the dorsal gland of the springbok, Antidorcas marsupialis. Tetrahedon Lett., 5221-5224.

Burger B. V., LeRoux M., Spies H. S. C., Truter V., and Bigalke R. C. (1981), Mammalian pheromone studies. 4. Terpenoid compounds and hydroxy esters from the dorsal glands of the springbok Antidorcas marsupialis. Z. Naturforsch. 36c, 340-343.

Butler L. I. and McDonough L. M. (1981), Insect pheromones: Evaporation rates of alcohols and acetates from natural rubber septa. J. Chem. Ecol. 7, $627-633$.

Cruz-Lopez I., Flavia E., Patricio L. R. A., and Morgan E. D. (2001). Secretion of stingless bees: the Dufour gland of Nannotrigona testaceicornis. J. Chem. Ecol. 27, 69-80.

Downing D. T. (1976), Mammalian waxes. In: Chemistry and Biochemistry of Natural Waxes (Kolattukudy P. E., ed). Elsevier, Amsterdam, pp. 34-71.

Frank A. (1941), Eigenartige Flugbahnen bei Hummelmännchen. Z. Vergl. Physiol. 28, 476-484.

Free J. B. (1987), Bumblebees: Mating behaviour. In: Pheromones of Social Bees (Free J. B., ed.). Chapman and Hall, London, pp. 164-172.

Fukushima J., Kuwamara Y., Yamada A., and Suzuki T. (1990), New non-cyclic homo-diterpene from the sting glands of Bracon hebetor Say (Hymenoptera, Braconidae). Agric. Biol. Chem. 54, 809-810.

Haahti E. O. A. and Fales H M. (1967), The uropygiols: identification of the unsaponifiable constituent of a diester wax from chicken preen glands. J. Lipid Res. $\mathbf{8}, 131-137$.

Haas A. (1949), Arttypische Flugbahnen von Hummelmännchen. Z. Vergl. Physiol. 31, 281-307.

Hovorka O., Urbanová K., and Valterová I.(1998), Premating behavior of Bombus confusus males and analysis of their labial gland secretion. J. Chem. Ecol. 24, 183-193.

Howard R. W., Baker J. E., and Morgan E. D. (2003), Novel Diterpenoids and Hydrocarbons in the Dufour gland of the Ectoparasitoid Habrobracon hebetor (Say) (Hymenoptera: Braconidae). Arch. Insect Biochem. Physiol. 54, 95-109.

Ibrahim S. A., Avery J. W., Weldon P. J., and Wheeler J. W. (1998), Age-class differences in lipids from the paracloacal glands of the American alligator (Alligator missippiensis). Z. Naturforsch. 53c, 201-209.

Jacob J. (1976), Bird waxes. In: Chemistry and Biochemistry of Natural Waxes (Kolattukudy P. E., ed). Elsevier, Amsterdam, pp. 94-146.

Kindl J., Hovorka O., Urbanová K., and Valterová I. (1999), Scent marking in male premating behavior of Bombus confusus. J. Chem. Ecol. 25, 1489-1500.

Kullenberg B., Bergström G., Bringer B., Carlberg B., and Cederberg B. (1973), Observations on scent marking by Bombus Latr., and Psithyrus Lep. Males (Hym., Apidae) and localisation of site of production of the secretion. Zoon (Suppl. 1), 23-29.

Lloyd J. E. (1981), Sexual selection: Individuality, identification, and recognition in a bumblebee and other insects. Florida Entomol. 64, 89-107.

McDonough L. M., Brown D. F., and W. C. Aller (1989), Insect sex pheromones: effect of temperature on evaporation rates of acetates from rubber septa. J. Chem Ecol. 15, 779-790.

Morse D. H. (1982), Behavior and ecology of bumble bees. In: Social Insects, Vol. III (Hermann R. H., ed.). Academic Press, New York, pp. 245-322.

Oldham N. J., Morgan E. D., Gobin B., Schoeters E., and Billen J. (1994), Volatile secretions of an Old World army ant, Aenictus rotundatus, and chemotaxonomic implications of army ant Dufour gland chemistry. J. Chem. Ecol. 20, 3297-3305.

Pepe C., Dagaut, J., Scribe P., and Saliot A. (1993), Double bond location in monosaturated wax esters by gas chromatography/mass spectrometry of their dimethyl disulphide derivatives. Org. Mass Spectrom. 28, $1365-1367$.

Ross G. N., Fales H. M., Lloyd H. A., Jones T., Sokoloski E. A., Marshall-Batty K., and Blum M. S. (2001), Novel chemistry of abdominal defensive glands of nymphalid butterfly Agraulis vanillae. J. Chem. Ecol. 27, 1219-1228.

Schremmer F. (1972), Beobachtungen zum Paarungsverhalten der Männchen von Bombus confusus Schenk. Z. Tierpsychol. 31, 503-512.

Svensson B. G. (1979), Patrolling behaviour of bumble bee males (Hymenoptera, Apidae) in a subalpine/ alpine area, Swedish Lappland. Zoon 7, 67-94.

Svensson B. G. and Bergström G. (1977), Volatile marking secretions from the labial gland of North European Pyrobombus D. T. males (Hymenoptera, Apidae). Insectes Sociaux 24, 213-224.

Svensson B. G. and Bergström G. (1979), Marking pheromones of Alpinobombus males. J. Chem. Ecol. 5, $603-615$.

Valterová I. and Urbanová K. (1997), Chemiké signály cmeláku (Chemical signals of bumble bees). Chem. Listy 91, 846-857 (in Czech).

Vermeer C. P., Nastold P., and Jetter R. (2003), Homologous very-long-chain 1,3-alkendiols and 3-hydroxyaldehydes in leaf cuticular waxes of Ricinus communis L. Phytochemistry 62, 433-438.

Villabos E. M. and Shelly T. E. (1987), Observations on the behavior of male Bombus sonorus (Hymenoptera: Apidae). J. Kansas Entomol. Soc. 60, 541-548.

Waterhouse J. S., Ke I., Pickett J. A., and Weldon P. J. (1996), Volatile components in dorsal gland secretions of the collared peccary, Tayassu tajacu (Tayassuidae, Mammalia). J. Chem. Ecol. 22, 1307-1314.

Waterhouse J. S., Hudson M., Pickett J. A., and Weldon P. J. (2001), Volatile compounds in dorsal secretions of the white-lipped peccary, Tayassu peccari, from Bolivia. J. Chem. Ecol. 27, 2459-2469.

Williams P. (1991), The bumble bees of the Kashmir Himalaya (Hymenoptera: Apidae, Bombini). Bull. Br. Mus. (Nat. Hist.) Entomol. 60, 1-204. 